\title{
SOBRE FINEO, TÍO DE ANDRÓMEDA, EN LOPE DE VEGA
}

José Dominguez Caparrós

$U N E D$

Tratando de hacer un comentario del soneto de Lope de Vega titulado «De Andrómeda» (Obras poéticas, I: 73-74), consulté el estudio que José M. de Cossío (1952) hace del extenso poema que Lope de Vega dedica al mismo asunto en La Filomena (Obras poéticas, I: 726-748). Al hablar de las invenciones que Lope de Vega introduce en el mito, dice:

«La invención menos feliz de la fábula es la introducción de un tío de Andrómeda, al que llama Fineo y supone enamorado de su sobrina; todo para aprovechar este elemento novelesco al ir Perseo al combate con el monstruo marino y, sobre todo, para aguar las fiestas de las bodas con un homicidio frustrado, del que Perseo no toma más venganza que dejar con vida al culpable para que muera de remordimiento. La tendencia de resolver los temas mitológicos en fábulas novelescas, en narraciones, pudiéramos decir, contemporáneas, que ya he notado en Lope, se ilumina clarísimamente en este desdichado episodio, propio de una comedia de las que Lope escribía en veinticuatro horas.» (Cossio, 1952: 334.)

Parece desprenderse de las palabras de José M." de Cossío que el tal tío nunca existió en el mito $o$, al menos, que no tuvo el papel de antagonista de Perseo como enamorado de Andrómeda. En cualquier caso, creo que conviene advertir al lector de la obra de Cossío, si es que nadie se lo ha señalado ya o no lo ha notado por sí mismo, sobre la necesidad de algunas matizaciones.

Veamos, primero, cuál es el papel de Fineo en el poema La Andrómeda, 
que es al que se refiere Jose $M{ }^{a}{ }^{a}$ de Cossío. En el momento culminante de la acción, cuando el monstruo va a atacar a Andrómeda - Perseo ya la ha pedido por esposa a Cefeo, padre de Andrómeda-, Fineo está entre el público, y es presentado como enamorado y cobarde:

estaba, entre los deudos admirados, atónito Fineo, previniendo envidia al joven, porque amor tenia, si puede haber amor y cobardia. (vv.621-624)

Más adelante, en el banquete de bodas, Fineo ataca a Perseo; éste responde y lo deja herido. Fineo pide clemencia - nótese el rasgo de cobardía-, pero Perseo le enseña la cabeza de Medusa, y el cobarde amante queda petrificado:

Porque mostrando al miserable amante
la gorgona cabeza de Medusa,
en piedra le volvió, segundo Atalante,
el alma, por los músculos difusa. (vv. 769-772)

A la vista de este final - que concuerda con el que Ovidio, según indicaré después, da a Fineo- no se entiende cómo José M. a de Cossío diga que lo deja vivo para que "muera de remordimiento". Parece que Cossío se ha quedado, en su lectura, en los versos en que Fineo, cobarde, pide a Perseo que le deje con vida. Los versos 757-760 reproducen las palabras de Fineo:

"No me mates, valiente semideo, déjame vivo; que es mayor venganza la que te dan de mi los altos cielos, pues tengo de morir de envidia y celos.»

Hay, pues, dos puntos importantes en los que José M.a de Cossío no explica satisfactoriamente el papel de Fineo en el poema de Lope de Vega; 1) el creer que Fineo es invención de Lope; 2) el decir que Fineo no muere en La Andrómeda, de Lope. Respecto del segundo punto, ya se ha visto que Fineo, en el poema de Lope, queda petrificado, como en la narración de 
Ovidio. Además, cuando José M. a de Cossío habla de desdichado episodio propio de una comedia, hay que pensar más bien en el tratamiento que el mismo Lope da al personaje de Fineo en la comedia mitológica El Perseo -obra que Cossio, por no estudiar el teatro, no menciona en su trabajo-; no en el papel del tío de Andrómeda en el poema incluido en La Filomena, que no tiene acusados rasgos dramáticos y se ajusta a su función en el relato mítico. Lope, incluso, reduce la extensión de su tratamiento y detalles, en comparación con Ovidio. Veamos ahora algunos datos que apoyan las afirmaciones anteriores.

Ovidio dedica nada menos que los 235 primeros versos del libro $\mathrm{V}$ de sus Metamorfosis a la batalla de los partidarios de Fineo contra Perseo, al final del banquete de bodas. La batalla tiene aires épicos, y Fineo queda convertido en una estatua en la que se percibe su gesto cobarde, su cara suplicante, sus manos sumisas y su actitud servil. Que Fineo no se hubiera atrevido a liberar a Andrómeda, se lo reprocha su hermano Cefeo ( Met., $\mathrm{V}$, 22-30).

En su magnífica sintesis de Mitología clásica, Antonio Ruiz de Elvira habla de Fineo, tío y prometido de Andrómeda, el cual, en el banquete, «aunque nada había hecho para salvarla, reclama ahora a Andrómeda como suya» (1975: 161). En la lucha, Fineo queda petrificado junto a sus compañeros.

El mitógrafo del Siglo de Oro, Juan Pérez de Moya, en su Philosophia Secreta (1585), habla también del compromiso anterior de Andrómeda con Fineo: "Y aunque estaba prometida a Fineo, viendo que no se atrevía a librarla, no sólo se la prometieron a Perseo por su mujer, / ... / (1585, II: 170). También aparece la batalla entre Perseo y Fineo (1585, II: 171).

Sólo fray Baltasar de Vitoria (Teatro de los dioses de la gentilidad, 1620) no menciona a Fineo en relación con la historia de Andrómeda.

Por supuesto, los diccionarios modernos de mitología hablan de Fineo al tratar el tema de Andrómeda: J. Humbert (1982: 135), P. Grimal (1982: 203).

A la vista de estos datos, hay que concluir que Lope de Vega sigue el mito clásico en lo que respecta al papel del enamorado Fineo, tío de Andrómeda, y a su combate y trágico final, petrificado. Recoge, igualmente, la característica de su cobardía, insinuada por Ovidio.

Las palabras de José M. " de Cossío relacionando el «desdichado lance» con las comedias que Lope escribía en veinticuatro horas, pueden justificarse si se refirieran a la pieza mitológica El Perseo. Aqui ya no se trata de un lance, sino de un personaje que aparece en la obra con un papel destacado en la estructura de la misma. El Fineo de la comedia no tiene casi nada que ver con el de la narración mitológica, salvo que también está enamorado de Andrómeda. En el acto segundo aparece hablando de Andrómeda con Medusa, antes de ser ésta muerta por Perseo, y después con Atalante (Atlas), que vaticina un negro futuro a sus amores. En el acto tercero, Fineo declara 
sus amores a Andrómeda, y, cuando ésta es atada a la roca, lo único que hace Fineo es pedir clemencia a los dioses y volverse loco. Hasta que Perseo le devuelva el sano juicio valiéndose de su espejo mágico, aparecerá en la escena «en caballo de caña». No es cobarde, es loco, e intenta la liberación de Andrómeda con una pasta, hecha de agujas y alfileres, contra el monstruo. La necesidad genérica de un final feliz hace que Perseo se case con Andrómeda, y Fineo, curado de su locura, con Laura. Aquí sí aprovecha Lope de Vega la figura de Fineo para construir el esquema dramático, inventándose todo lo que quiere.

Que Lope no tiene empacho en inventar detalles, parece evidente cuando en la misma comedia El Perseo se dice que la antagonista de la madre de Andrómeda es Latona, madre de Apolo, y no las nereidas o Hera (Juno), según la tradición mitológica. En palabras de Andrómeda:

Latona, madre de Apolo, aunque diosa, con intento de vengarse de mi madre, estas crueldades ha hecho, indignas de su deidad. (El Perseo: 38)

Y en boca de Fineo:

Si de Andrómeda la madre tuvo aquel soberbio intento de competir con Latona. (El Perseo: 39)

En ninguna más de las obras mencionadas en esta nota aparece la madre de Apolo como rival de Casiopea, madre de Andrómeda.

Al margen de las precisiones al comentario de José $M .{ }^{a}$ de Cossío a $\mathbf{L a}$ Andrómeda, hay en este poema un verso que merece ser destacado, por cuanto que es señal, en mi opinión, del saber mitológico de Lope de Vega. Se trata del Fineo, tío de Andrómeda, citando a otro Fineo, el adivino ciego que aparece en el viaje de los argonautas y que es acosado por las arpías. En el parlamento de Fineo con Perseo, éste es comparado con las rapaces aves mitológicas:

Mozo extranjero, que mi dulce esposa, 
valiente, por encanto me has quitado, más ave que hombre al fin, y ave engañosa, de las arpias de Fineo traslado. (vv. 745-748)

Lope de Vega está diciendo que él no confunde a los dos personajes mitológicos, pues el uno comenta, cita, al otro. Sí los confunde, por ejemplo, Juan Pérez de Moya (1585, II: 108). Grimal, en su diccionario, explica muy bien las diferencias entre uno y otro Fineo. Puede verse también Humbert (1982: 273-274) y Ruiz de Elvira (1975: 280), para el mito de Fineo y las arpias.

\section{REFERENCIAS BIBLIOGRÁFICAS}

Cossio, José M.^ DE, Fábulas mitológicas en España. Madrid, Espasa-Calpe, 1952.

Grimal, Pierre, Diccionario de mitologia griega y romana.Barcelona, Paidós, 1982 (reimpresión).

Humbert, JuAn, Mitologia griega y romana. Barcelona, G. Gili, 1988, 17." tirada.

Ovidio Nasón, P., Metamorfosis. Texto revisado y traducido por Antonio Ruiz de Elvira, vol. I. Barcelona, Alma Mater, 1964.

Pérez de Moya, Juan, Philosophia Secreta, 1585. Madrid, 1928, 2 vols. Los Clásicos Olvidados, VI y VII.

Ruiz de Elvira, Antonio, Mitología Clásica. Madrid, Gredos, 1975.

VEGA, LOPE DE, Obras poéticas, I. Edición, introducción y notas de José Manuel Blecua, Barcelona, Planeta (1969), 1974, 2." ed.

- El Perseo, en Obras de Lope de Vega, vol. XIV. Madrid, Atlas, 1966, BAE, CXC, 5-50.

Vitoria, Fray Baltasar DE, Teatro de los dioses de la gentilidad, 1620. Madrid, Imprenta Real, 1673, 2 vols. 